\title{
Symbols and Notation
}

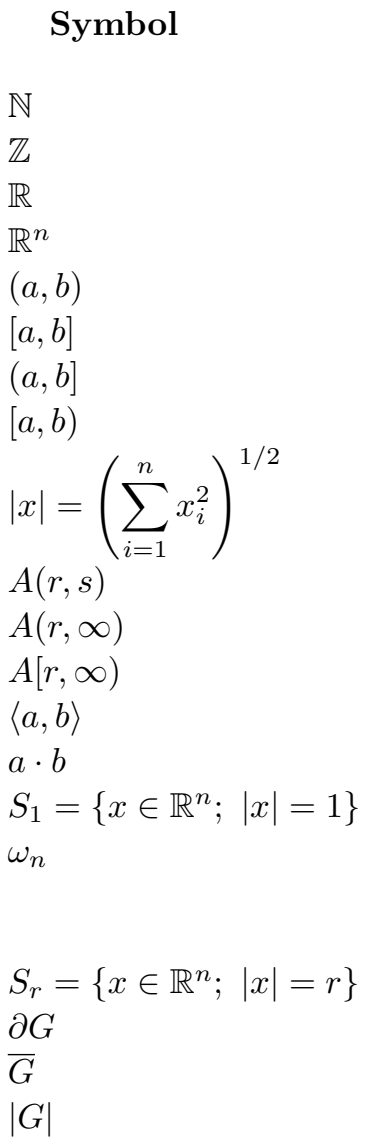

\section{Meaning}

set of all positive integers

set of all integers

set of all real numbers

real $n$-dimensional Euclidean space

open interval $\{t \in \mathbb{R} ; a<t<b\}$

closed interval $\{t \in \mathbb{R} ; a \leq t \leq b\}$

interval $\{t \in \mathbb{R} ; a<t \leq b\}$

interval $\{t \in \mathbb{R} ; a \leq t<b\}$

Euclidean length of $x \in \mathbb{R}^{n}$

annular domain $\left\{x \in \mathbb{R}^{n} ; r<|x|<s\right\}$

exterior domain $\left\{x \in \mathbb{R}^{n} ; r<|x|\right\}$

exterior domain $\left\{x \in \mathbb{R}^{n} ; r \leq|x|\right\}$

scalar product of $a \in \mathbb{R}^{N}$ and $b \in \mathbb{R}^{N}$

scalar product of $a \in \mathbb{R}^{N}$ and $b \in \mathbb{R}^{N}$

unit sphere in $\mathbb{R}^{n}$

surface area of unit sphere $S_{1}$, that is,

$$
\omega_{n}=\frac{2 \pi^{n / 2}}{\Gamma(n / 2)}(\Gamma(s): \text { gamma function })
$$

$(n-1)$-dimensional sphere with radius $r$

boundary of a domain $G \subset \mathbb{R}^{n}$

closure of a domain $G \subset \mathbb{R}^{n}$

volume of a domain $G \subset \mathbb{R}^{n}$, that is,

$$
|G|=\int_{G} d x
$$




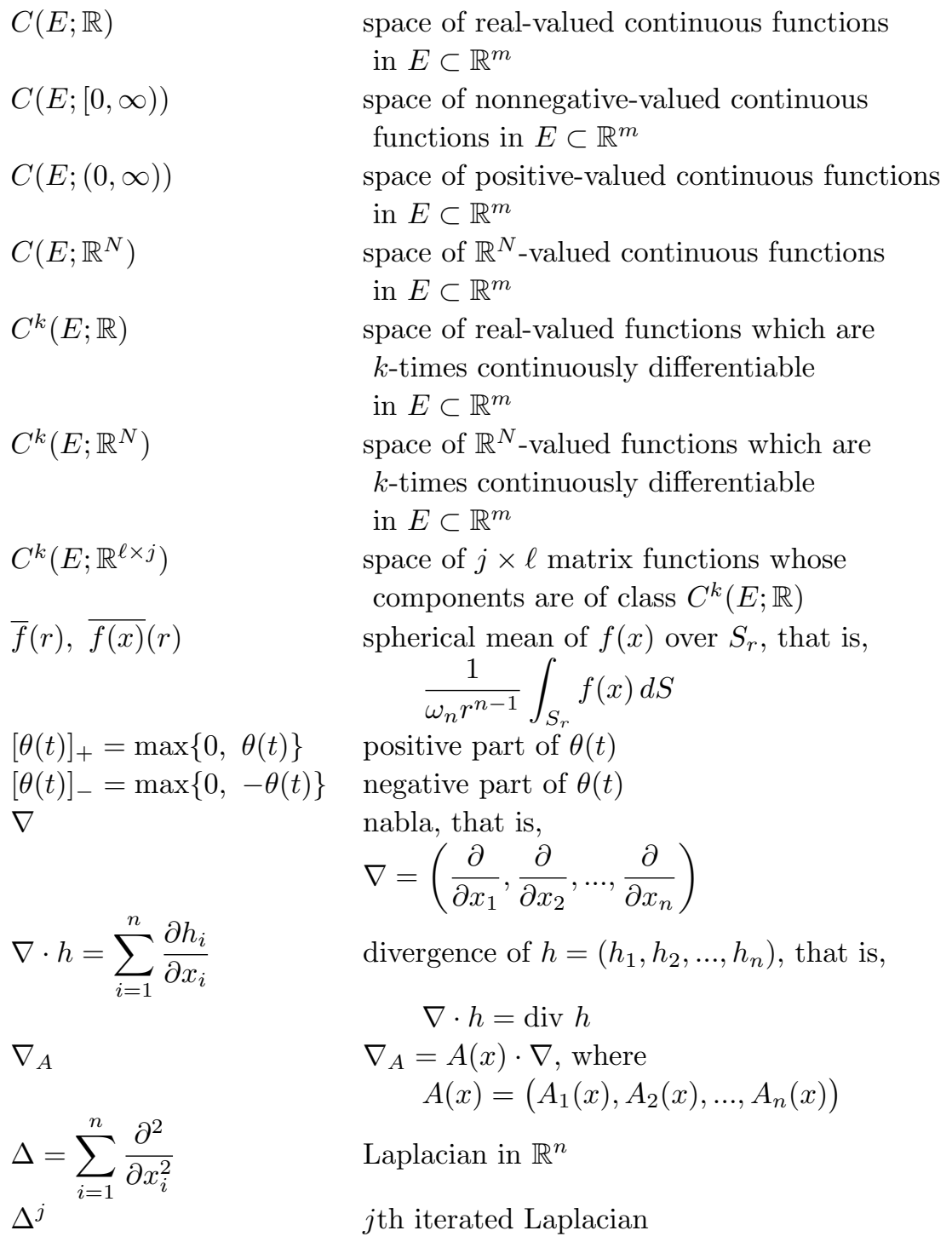




\section{Bibliography}

[1] Adams, R. A. and Fournier, J. J. F. (2003). Sobolev Spaces, Second Edition (Academic Press).

[2] Agarwal, R. P., Bochner, M., Grace, S. R. and O'Regan, D. (2005). Discrete Oscillation Theory (Hindawi Publishing Corporation, New York).

[3] Agarwal, R. P., Bochner, M. and Li, W.-T. (2004). Nonoscillation and Oscillation: Theory for Functional Differential Equations (Marcel Dekker, Inc., New York).

[4] Agarwal, R. P., Grace, S. R. and O'Regan, D. (2000). Oscillation Theory for Difference and Functional Differential Equations (Kluwer Academic Publishers, Dordrecht).

[5] Agarwal, R. P., Grace, S. R. and O'Regan, D. (2002). Oscillation Theory for Second Order Linear, Half-Linear, Superlinear and Sublinear Dynamic Equations (Kluwer Academic Publishers, Dordrecht).

[6] Agarwal, R. P., Grace, S. R. and O'Regan, D. (2003). Oscillation Theory for Second Order Dynamic Equations (Taylor \& Francis, Ltd., London).

[7] Agarwal, R. P., Meng, F. W. and Li, W. N. (2002). Oscillation of solutions of systems of neutral type partial functional differential equations, Comput. Math. Appl. 44, pp. 777-786.

[8] Agmon, S. (1965). Lectures on Elliptic Boundary Value Problems (Van Nostrand Co., Inc.).

[9] Allegretto, W. (1974). Oscillation criteria for quasilinear equations, Canad. J. Math. 26, pp. 931-947.

[10] Allegretto, W. (1976). Nonoscillation theory of elliptic equations of order 2n, Pacific J. Math. 64, pp. 1-16.

[11] Allegretto, W. (1976). Oscillation criteria for semilinear equations in general domains, Canad. Math. Bull. 19, pp. 137-144.

[12] Allegretto, W. (1977). A Kneser theorem for higher order elliptic equations, Canad. Math. Bull. 20, pp. 1-8.

[13] Allegretto, W. (1977). Nonoscillation criteria for elliptic equations in conical domains, Proc. Amer. Math. Soc. 63, pp. 245-250.

[14] Allegretto, W. (2000). Sturm type theorems for solutions of elliptic nonlinear problems, NoDEA Nonlinear Differential Equations Appl. 7, pp. 309- 
321.

[15] Allegretto, W. (2001). Sturm theorems for degenerate elliptic equations, Proc. Amer. Math. Soc. 129, pp. 3031-3035.

[16] Allegretto, W. and Huang, Y. X. (1998). A Picone's identity for the $p$ Laplacian and applications, Nonlinear Anal. 32, pp. 819-830.

[17] Allegretto, W. and Huang, Y. X. (1999). Principal eigenvalues and Sturm comparison via Picone's identity, J. Differential Equations 156, pp. 427438.

[18] Altin, A. (1982). Comparison and oscillation theorems for singular ultrahyperbolic equations, Comm. Fac. Sci. Univ. Ankara Sér. A 1 Math. 31, pp. 47-57.

[19] Angenent, S. (1991). Nodal properties of solutions of parabolic equations, Rocky Mountain J. Math. 21, pp. 585-592.

[20] Aviles, P. (1982). A study of the singularities of solutions of a class of nonlinear elliptic partial differential equations, Comm. Partial Differential Equations 7, pp. 609-643.

[21] Bainov, D. D., Kamont, Z. and Minchev, E. (1996). Monotone iterative methods for impulsive hyperbolic differential-functional equations, J. Comput. Appl. Math. 70, pp. 329-347.

[22] Bainov, D. and Minchev, E. (1996). Oscillation of solutions of impulsive parabolic equations, J. Comput. Appl. Math. 69, pp. 207-214.

[23] Bainov, D. and Minchev, E. (1996). Oscillation of solutions of impulsive nonlinear parabolic differential-difference equations, Internat. J. Theoret. Phys. 35, pp. 207-215.

[24] Bainov, D. and Minchev, E. (1998). Forced oscillations of solutions of impulsive nonlinear parabolic differential-difference equations, J. Korean Math. Soc. 35, pp. 881-890.

[25] Bainov, D. D. and Mishev, D. P. (1991). Oscillation Theory for Neutral Differential Equations with Delay (Adam Hilger, Ltd., Bristol).

[26] Bainov, D. D. and Mishev, D. P. (1995). Oscillation Theory of OperatorDifferential Equations (World Scientific Publishing Co., Inc., River Edge, NJ).

[27] Ball, J. M. (1973). Stability theory for an extensible beam, J. Differential Equations 14, pp. 399-418.

[28] Barański, F. (1976). The mean value theorem and oscillatory properties of certain elliptic equations in three dimensional space, Comment. Math. Prace Mat. 19, pp. 13-14.

[29] Bateman, H. (1933). Logarithmic solutions of Bianchi's equation, Proc. Nat. Acad. Sci. U.S.A. 19, pp. 852-854.

[30] Benchohra, M., Henderson, J. and Ntouyas, S. (2006). Impulsive Differential Equations and Inclusions (Hindawi Publishing Corporation, New York).

[31] Bianchi, L. (1895). Il metodo di Riemann esteso alla integrazione della equazione: $\frac{\partial^{n} u}{\partial x_{1} \partial x_{2} \cdots \partial x_{n}}=M u$, Atti Real. Accad. Lincei, Rend. 4, pp. $8-18$. 
[32] Bognár, G. and Došlý, O. (2003). The application of Picone-type identity for some nonlinear elliptic differential equations, Acta Math. Univ. Comenian. 72, pp. 45-57.

[33] Borzymowski, A. (1980). A Goursat problem for a polyvibrating equation of D. Mangeron, Funkcial. Ekvac. 23, pp. 1-16.

[34] Bouchekif, M. (1991). Comportement oscillatoire des solutions d'une équation elliptique, Riv. Mat. Pura Appl. 9, pp. 69-79.

[35] Bouchekif, M. and Górowski, J. (1990). Propriétés oscillatoires des solutions de certaines équations elliptiques, Facta Univ. Ser. Math. Inform. 5, pp. 67-79.

[36] Bugir, M. K. (1990). Oscillation properties of solutions of linear differential equations in space of constant curvature, Differ. Equ. 26, pp. 1461-1466.

[37] Bugir, M. K. (1990). A remark on the conditions for the oscillation of solutions of nonlinear differential equations, Ukrainian Math. J. 42, pp. 404-409.

[38] Bugir, M. K. (1992). A study of the nonoscillatory character of solutions of partial differential equations by the method of separation of variables, Ukrainian Math. J. 44, pp. 278-283.

[39] Bugir, M. K. and Dobrotvor, I. G. (1988). Oscillability of Solutions of Differential Equations in Spaces of Constant Curvature, Akad. Nauk Ukrain. SSR Inst. Mat. Preprint No. 62.

[40] Bykov, Ya. V. and Kultaev, T. Ch. (1983). Oscillation of solutions of a class of parabolic equations, Izv. Akad. Nauk Kirgiz. SSR 6, pp. 3-9.

[41] Bykova, L. Ya. and Marusich, A. I. (1989). Oscillation properties of solutions of a class of parabolic equations with delay, Izv. Akad. Nauk Kirgiz. SSR 2, pp. 3-10.

[42] Cannon, J. R. (1984). The One-Dimensional Heat Equation (AddisonWesley Publishing Company, Inc.).

[43] Cazenave, T. and Haraux, A. (1984). Propriétés oscillatoires des solutions de certaines équations des ondes semi-linéaires, C. R. Acad. Sci. Paris Sér. I Math. 298, pp. 449-452.

[44] Cazenave, T. and Haraux, A. (1987). Oscillatory phenomena associated to semilinear wave equations in one spatial dimension, Trans. Amer. Math. Soc. 300, pp. 207-233.

[45] Cazenave, T. and Haraux, A. (1988). Some oscillatory properties of the wave equation in several space dimensions, J. Funct. Anal. 76, pp. 87-109.

[46] Chan, C. Y. (1982). Singular and unbounded matrix solutions for both time-dependent matrix and vector differential systems, J. Math. Anal. Appl. 87, pp. 147-157.

[47] Chan, C. Y. and Young, E. C. (1973). Unboundedness of solutions and comparison theorems for time-dependent quasilinear differential matrix inequalities, J. Differential Equations 14, pp. 195-201.

[48] Chan, C. Y. and Young, E. C. (1975). Singular matrix solutions for timedependent fourth order quasilinear matrix differential inequalities, J. Differential Equations 18, pp. 386-392.

[49] Chen, M. -P. and Zhang, B. G. (1995). Oscillation criteria for a class of 
perturbed Schrödinger equations, Hiroshima Math. J. 25, pp. 207-214.

[50] Cheng, S. S. (2003). Partial Difference Equations (Taylor \& Francis, London).

[51] Cheng, S. S. and Zhang, B. G. (1994). Qualitative theory of partial difference equations (I): oscillation of nonlinear partial difference equations, Tamkang J. Math. 25, pp. 279-288.

[52] Coddington, E. A. and Levinson, N. (1955). Theory of Ordinary Differential Equations (McGraw-Hill, New York).

[53] Conlan, J. and Diaz, J. B. (1963). Existence of solutions of an $n$-th order hyperbolic partial differential equation, Contrib. Differential Equations 2, pp. $277-289$.

[54] Courant, R. and Hilbert, D. (1966). Methods of Mathematical Physics, Vol. $I$ (Interscience, New York).

[55] Cui, B. T. (1991). Oscillation theorems of nonlinear parabolic equations of neutral type, Math. J. Toyama Univ. 14, pp. 113-123.

[56] Cui, B. T. (1992). Oscillation properties for parabolic equations of neutral type, Comment. Math. Univ. Carolinae 33, pp. 581-588.

[57] Cui, B. T., Deng, F. Q., Li, W. N. and Liu, Y. Q. (2005). Oscillation problems for delay parabolic systems with impulses, Dyn. Contin. Discrete Impuls. Syst. Ser. A Math. Anal. 12, pp. 67-76.

[58] Cui, B. T., Liu, Y. Q. and Deng, F. Q. (2003). Some oscillation problems for impulsive hyperbolic differential systems with several delays, Appl. Math. Comput. 146, pp. 667-679.

[59] Deng, L. H. (2002). Oscillation criteria for certain hyperbolic functional differential equations with Robin boundary condition, Indian J. Pure Appl. Math. 33, pp. 1137-1146.

[60] Deng, L. H. and Ge, W. G. (2001). Oscillation for certain delay hyperbolic equations satisfying the Robin boundary condition, Indian J. Pure Appl. Math. 32, pp. 1269-1274.

[61] Deng, L. H. and Ge, W. G. (2001). Oscillation criteria of solutions for impulsive delay parabolic equation, Acta Math. Sinica (Chin. Ser.) 44, pp. 501-506.

[62] Deng, L. H., Ge, W. G. and Wang, P. G. (2003). Oscillation of hyperbolic equations with continuous deviating arguments under the Robin boundary condition, Soochow J. Math. 29, pp. 1-6.

[63] Deng, L. H., Tan, Y. M. and Yu, Y. H. (2002). Oscillation criteria of solutions for a class of impulsive parabolic differential equations, Indian $J$. Pure Appl. Math. 33, pp. 1147-1153.

[64] Dobrotvor, I. G. (1984). Oscillation properties of the solutions of equations with a polyharmonic operator in the space $E^{n}$, Ukrainian Math. J. 36, pp. 230-232.

[65] Domšlak, Ju. I. (1970). On the oscillation of solutions of vector differential equations, Soviet Math. Dokl. 11, pp. 839-841.

[66] Domshlak, Yu. I. (1971). Oscillatory properties of solutions of vector differential equations, Differ. Uravn. 7, pp. 961-969: Differ. Equ. 7, pp. 728-734.

[67] Domshlak, Yu. I. and Tamoev, G. I. (1981). A vector analogue of the 
Picone-Hartman-Wintner comparison theorem for operator-partial differential equations and its application to the investigation of ultrahyperbolic equations, Izv. Akad. Nauk Azerbaidzhan. SSR Ser. Fiz.-Tekhn. Mat. Nauk 2, pp. 21-26.

[68] Došlý, O. (2002). The Picone identity for a class of partial differential equations, Math. Bohem. 127, pp. 581-589.

[69] Došlý, O. (2004). Half-linear Differential Equations, Handbook of Differential Equations: Ordinary Differential Equations, Volume 1 (Elsevier B. V., Amsterdam)

[70] Došlý, O. and Mařŕk, R. (2001). Nonexistence of positive solutions for PDE's with p-Laplacian, Acta Math. Hungar. 90, pp. 89-107.

[71] Došlý, O. and Řehák, P. (2005). Half-linear Differential Equations (NorthHolland Mathematics Studies, 202, Elsevier Science B.V., Amsterdam).

[72] Dunninger, D. R. (1969). Sturmian theorems for parabolic inequalities, Rend. Accad. Sci. Fis. Mat. Napoli 36, pp. 406-410.

[73] Dunninger, D. R. (1995). A Sturm comparison theorem for some degenerate quasilinear elliptic operators, Boll. Un. Mat. Ital. A (7) 9, pp. 117-121.

[74] El-Sayed, M. A. (1993). An oscillation criterion for forced second order linear differential equation, Proc. Amer. Math. Soc. 118, pp. 814-817.

[75] Erbe, L. H., Freedman, H. I., Liu, X. Z. and Wu, J. H. (1991). Comparison principles for impulsive parabolic equations with applications to models of single species growth, J. Austral. Math. Soc. Ser. B 32, pp. 382-400.

[76] Erbe, L. H., Kong, Q. and Zhang, B. G. (1995). Oscillation Theory for Functional Differential Equations (Marcel Dekker, Inc., New York).

[77] Evans, L. C. (1998). Partial Differential Equations (American Mathematical Society, Providence, Rhode Island).

[78] Feireisl, E. and Herrmann, L. (1992). Oscillations of a nonlinearly damped extensible beam, Appl. Math. 37, pp. 469-478.

[79] Fitzgibbon, W. E. (1982). Global existence and boundedness of solutions to the extensible beam equations, SIAM J. Math. Anal. 13, pp. 739-745.

[80] Frydrych, Z. (1975). On certain oscillatory properties for solutions of an equation with a biharmonic leading part, Ann. Polon. Math. 30, pp. 225228.

[81] Fu, X. and Liu, X. (1997). Oscillation criteria for impulsive hyperbolic systems, Dyn. Contin. Discrete Impuls. Syst. 3, pp. 225-244.

[82] Fu, X., Liu, X. and Sivaloganathan, S. (2001). Oscillation criteria for impulsive parabolic systems, Appl. Anal. 79, pp. 239-255.

[83] Fu, X., Liu, X. and Sivaloganathan, S. (2002). Oscillation criteria for impulsive parabolic differential equations with delay, J. Math. Anal. Appl. 268, pp. 647-664.

[84] Fu, X. and Zhang, L. Q. (2004). Forced oscillation for impulsive hyperbolic boundary value problems with delay, Appl. Math. Comput. 158, pp. 761780.

[85] Fu, X. and Zhuang, W. (1995). Oscillation of certain neutral delay parabolic equations, J. Math. Anal. Appl. 191, pp. 473-489.

[86] Fujita, H. (1966). On the blowing up of solutions of the Cauchy problem 
for $u_{t}=\Delta u+u^{1+\alpha}$, J. Fac. Sci. Univ. Tokyo Sect. I 8, pp. 109-124.

[87] Georgiou, D. and Kreith, K. (1985). Functional characteristic initial value problems, J. Math. Anal. Appl. 107, pp. 414-424.

[88] Glazman, I. M. (1965). Direct Methods of Qualitative Spectral Analysis of Singular Differential Operators (Israel Program for Scientific Translations, Jerusalem).

[89] Glick, I. I. (1963). On an analog of the Euler-Cauchy polygon method for the partial differential equation $u_{x_{1} \cdots x_{n}}=f$, Contrib. Differential Equations 2, pp. 1-59.

[90] Gopalsamy, K. (1992). Oscillations in parabolic neutral systems, MiniConference on Free and Moving Boundary and Diffusion Problems (Canberra, 1990), Proc. Centre Math. Appl. Austral. Nat. Univ., Austral. Nat. Univ., Canberra, pp. 128-141.

[91] Gorbaĭchuk, V. I. and Dobrotvor, I. G. (1980). Conditions for the oscillation of solutions of a class of elliptic equations of high orders with constant coefficients, Ukrainian Math. J. 32, pp. 385-391.

[92] Gorbaĭchuk, V. I. and Dobrotvor, I. G. (1982). Investigation of the oscillation of solutions of a class of equations with biharmonic operator, using the mean-value theorem, Mat. Fiz. 31, pp. 71-75.

[93] Górowski, J. (1985). The mean value theorem and oscillatory behaviour for solutions of certain elliptic equations, Math. Nachr. 122, pp. 259-265.

[94] Györi, I. and Ladas, G. (1991). Oscillation Theory of Delay Differential Equations (Clarendon Press, Oxford).

[95] Haraux, A. and Komornik, V. (1985). Oscillations of anharmonic Fourier series and the wave equation, Rev. Mat. Iberoamericana 1, pp. 57-77.

[96] Haraux, A. and Zuazua, E. (1988). Super-solutions of eigenvalue problems and the oscillation properties of second order evolution equations, J. Differential Equations 74, pp. 11-28.

[97] Hardy, G., Littlewood, J. E. and Pólya, G. (1988). Inequalities, Second Edition (Cambridge University Press).

[98] Hartman, P. and Wintner, A. (1955). On a comparison theorem for selfadjoint partial differential equations of elliptic type, Proc. Amer. Math. Soc. 6, pp. 862-865.

[99] Headley, V. B. (1969). A monotonicity principle for eigenvalues, Pacific J. Math. 30, pp. 663-668.

[100] Headley, V. B. (1969). Elliptic equations of order 2m, J. Math. Anal. Appl. 25, pp. 558-568.

[101] Headley, V. B. (1986). Sharp nonoscillation theorems for even-order elliptic equations, J. Math. Anal. Appl. 120, pp. 709-722.

[102] Headley, V. B. (1989). Nonoscillation theorems for nonselfadjoint evenorder elliptic equations, Math. Nachr. 141, pp. 289-297.

[103] Hecquet, G. (1977). Etude de quelques problèmes d'existence globale concernant l'équation $\frac{\partial^{r+s} u}{\partial x^{r} \partial y^{s}}=f\left(x, y, u, \frac{\partial u}{\partial x}, \frac{\partial u}{\partial y}, \ldots, \frac{\partial^{p+q} u}{\partial x^{p} \partial y^{q}}, \ldots\right)$ 
$\left\{\begin{array}{l}0 \leq p \leq r \\ 0 \leq q \leq s \\ p+q<r+s\end{array}\right.$, Ann. Mat. Pura Appl. 113, pp. 173-197.

[104] Hörmander, L. (1963). Linear Partial Differential Operators (SpringerVerlag, Berlin).

[105] Hsiang, W. -T. and Kwong, M. K. (1980). A comparison theorem for the first nodal line of the solutions of quasilinear hyperbolic equations with non-increasing initial values, Proc. Roy. Soc. Edinburgh Sect. A 86, pp. 139-151.

[106] Hsiang, W. -T. and Kwong, M. K. (1982). On the oscillation of nonlinear hyperbolic equations, J. Math. Anal. Appl. 85, pp. 31-45.

[107] Hsiang, W. -T. and Kwong, M. K. (1982). Oscillation of second-order hyperbolic equations with non-integrable coefficients, Proc. Roy. Soc. Edinburgh Sect. A 91, pp. 305-313.

[108] Iraniparast, N. (1987). Qualitative behaviour of solutions of the Goursat problem for hyperbolic differential equations, Comput. Math. Appl. 13, pp. 889-900.

[109] Itô, S. (1957). Fundamental solutions of parabolic differential equations and boundary value problems, Japan. J. Math. 27, pp. 55-102.

[110] Jaroš, J. and Kusano, T. (1997). Second-order semilinear differential equations with external forcing terms, Sūrikaisekikenkyūsho Kōkyūroku, no. 984, pp. 191-197.

[111] Jaroš, J. and Kusano, T. (1999). A Picone type identity for second order half-linear differential equations, Acta Math. Univ. Comenian. 68, pp. 117121.

[112] Jaroš, J., Kusano, T. and Yoshida, N. (2000). Forced superlinear oscillations via Picone's identity, Acta Math. Univ. Comenian. 69, pp. 107-113.

[113] Jaroš, J., Kusano, T. and Yoshida, N. (2001). Picone-type inequalities for nonlinear elliptic equations and their applications, J. Inequal. Appl. 6, pp. 387-404.

[114] Jaroš, J., Kusano, T. and Yoshida, N. (2001). Oscillatory properties of solutions of superlinear-sublinear parabolic equations via Picone-type inequalities, Math. J. Toyama Univ. 24, pp. 83-91.

[115] Jaroš, J., Kusano, T. and Yoshida, N. (2002). Generalized Picone's formula and forced oscillations in quasilinear differential equations of the second order, Arch. Math. (Brno) 38, pp. 53-59.

[116] Jaroš, J., Kusano, T. and Yoshida, N. (2002). Picone-type inequalities for half-linear elliptic equations and their applications, Adv. Math. Sci. Appl. 12, pp. 709-724.

[117] Jaroš, J., Kusano, T. and Yoshida, N. (2002). Oscillation properties of solutions of a class of nonlinear parabolic equations, J. Comput. Appl. Math. 146, pp. 277-284.

[118] Jaroš, J., Kusano, T. and Yoshida, N. (2006). Picone-type inequalities for elliptic equations with first order terms and their applications, J. Inequal. Appl. 2006, pp. 1-17. 
[119] Jin, M. Z., Dong, Y. and Li, C. X. (1996). Forced oscillations of boundary value problems of higher order functional partial differential equations, Appl. Math. Mech. (English Ed.) 17, pp. 889-900.

[120] John, F. (1980). Partial Differential Equations, Third Edition (SpringerVerlag, New York).

[121] Kahane, C. (1973). Oscillation theorems for solutions of hyperbolic equations, Proc. Amer. Math. Soc. 41, pp. 183-188.

[122] Kamenev, I. V. (1978). An integral criterion for oscillation of linear differential equations of second order, Math. Zamtki 23, pp. 249-251: Math. Notes 23, pp. 136-138.

[123] Kartsatos, A. G. (1975) On $n$th order differential inequalities, J. Math. Anal. Appl. 52, pp. 1-9.

[124] Kiguradze, I. T. (1962). Oscillation properties of solutions of certain ordinary differential equations, Dokl. Akad. Nauk SSSR 144, pp. 33-36: Soviet Math. Dokl. 3, pp. 649-652.

[125] Kiguradze, I. T. (1964). On the oscillation of solutions of the equation $\frac{d^{m} u}{d t^{m}}+a(t)|u|^{n} \operatorname{sign} u=0$, Mat. Sb. 65, pp. 172-187.

[126] Kiguradze, T., Kusano, T. and Yoshida, N. (2002). Oscillation criteria for a class of partial functional-differential equations of higher order, J. Appl. Math. Stochastic Anal. 15, pp. 271-282.

[127] Kiguradze, T. and Stavroulakis, I. P. (2001). On oscillatory properties of solutions of higher order linear hyperbolic equations, Adv. Math. Sci. Appl. 11, pp. 645-672.

[128] Kitamura, Y. and Kusano, T. (1978). Nonlinear oscillation of a fourth order elliptic equation, J. Differential Equations 30, pp. 280-286.

[129] Kitamura, Y. and Kusano, T. (1978). An oscillation theorem for a sublinear Schrödinger equation, Utilitas Math. 14, pp. 171-175.

[130] Kitamura, Y. and Kusano, T. (1980). Oscillation criteria for semilinear metaharmonic equations in exterior domains, Arch. Rational Mech. Anal. 75, pp. 79-90.

[131] Kitamura, Y. and Kusano, T. (1980). Oscillation of first-order nonlinear differential equations with deviating arguments, Proc. Amer. Math. Soc. 78, pp. 64-68.

[132] Kobayashi, K. and Yoshida, N. (2000). Oscillations of solutions of initial value problems for parabolic equations, Math. J. Toyama Univ. 23, pp. 149-155.

[133] Kobayashi, K. and Yoshida, N. (2002). Unboundedness of solutions of timedependent differential systems of parabolic type, Math. J. Toyama Univ. 25, pp. 65-75.

[134] Kong, Q. (1999). Interval criteria for oscillation of second-order linear ordinary differential equations, J. Math. Anal. Appl. 229, pp. 258-270.

[135] Kopáčková, M. (1983). On periodic solution of a nonlinear beam equation, Appl. Math. 28, pp. 108-115.

[136] Kreith, K. (1969). Sturmian theorems for characteristic initial value problems, Atti Accad. Naz. Lincei Rend. Cl. Sci. Fis. Mat. Natur. 47, pp. 139- 
144.

[137] Kreith, K. (1969). Sturmian theorems for hyperbolic equations, Proc. Amer. Math. Soc. 22, pp. 277-281.

[138] Kreith, K. (1973). Oscillation Theory, Lecture Notes in Mathematics, Vol. 324 (Springer-Verlag, Berlin).

[139] Kreith, K. (1974). A nonselfadjoint dynamical system, Proc. Edinburgh Math. Soc. (2) 19, pp. 77-87.

[140] Kreith, K. (1975). Picone's identity and generalizations, Rend. Mat. 8, pp. 251-261.

[141] Kreith, K. (1981). A class of comparison theorems for non-linear hyperbolic initial value problems, Proc. Roy. Soc. Edinburgh Sect. A 87, pp. 189-191.

[142] Kreith, K., Kusano, T. and Yoshida, N. (1984). Oscillation properties of nonlinear hyperbolic equations, SIAM J. Math. Anal. 15, pp. 570-578.

[143] Kreith, K. and Ladas, G. (1985). Allowable delays for positive diffusion processes, Hiroshima Math. J. 15, pp. 437-443.

[144] Kreith, K. and Pagan, G. (1983). Qualitative theory for hyperbolic characteristic initial value problems, Proc. Roy. Soc. Edinburgh Sect. A 94, pp. 15-24.

[145] Kreith, K. and Swanson, C. A. (1985). Kiguradze classes for characteristic initial value problems, Comput. Math. Appl. 11, pp. 239-247.

[146] Kreith, K. and Travis, C. C. (1972). Oscillation criteria for selfadjoint elliptic equations, Pacific J. Math. 41, pp. 743-753.

[147] Kubiaczyk, I. and Saker, S. H. (2002). Oscillation of delay parabolic differential equations with several coefficients, J. Comput. Appl. Math. 147, pp. 263-275.

[148] Kuks, L. M. (1962). Sturm's theorem and oscillation of solutions of strongly elliptic systems, Soviet Math. Dokl. 3, pp. 24-27.

[149] Kuks, L. M. (1978). Unboundedness of solutions of high-order parabolic systems in the plane and a Sturm-type comparison theorem, Differ. Uravn. 14, pp. 878-884: Differ. Equ. 14, pp. 623-627.

[150] Kura, T. (1982). Oscillation criteria for a class of sublinear elliptic equations of the second order, Utilitas Math. 22, pp. 335-341.

[151] Kusano, T., Jaroš, J. and Yoshida, N. (2000). A Picone-type identity and Sturmian comparison and oscillation theorems for a class of half-linear partial differential equations of second order, Nonlinear Anal. 40, pp. 381-395.

[152] Kusano, T. and Naito, M. (1982). Oscillation criteria for a class of perturbed Schrödinger equations, Canad. Math. Bull. 25, pp. 71-77.

[153] Kusano, T. and Naito, Y. (1997). Oscillation and nonoscillation criteria for second order quasilinear differential equations, Acta Math. Hungar. 76, pp. 81-99.

[154] Kusano, T., Naito, Y. and Ogata, A. (1994). Strong oscillation and nonoscillation of quasilinear differential equations of second order, Differential Equations Dynam. Systems 2, pp. 1-10.

[155] Kusano, T. and Narita, M. (1977). Unboundedness of solutions of parabolic differential inequalities, J. Math. Anal. Appl. 57, pp. 68-75.

[156] Kusano, T. and Yoshida, N. (1975). Nonoscillation criteria for strongly 
elliptic systems, Boll. Un. Mat. Ital. (4) 11, pp. 262-265.

[157] Kusano, T. and Yoshida, N. (1980). Nonlinear oscillation criteria for singular elliptic differential operators, Funkcial. Ekvac. 23, pp. 135-142.

[158] Kusano, T. and Yoshida, N. (1981). Oscillation criteria for a class of nonlinear partial differential equations, J. Math. Anal. Appl. 79, pp. 236-243.

[159] Kusano, T. and Yoshida, N. (1985). Forced oscillations of Timoshenko beams, Quart. Appl. Math. 43, pp. 167-177.

[160] Kusano, T. and Yoshida, N. (1994). Oscillation of parabolic equations with oscillating coefficients, Hiroshima Math. J. 24, pp. 123-133.

[161] Kusano, T. and Yoshida, N. (1999). Oscillation criteria for a class of functional parabolic equations, J. Appl. Anal. 5, pp. 1-16.

[162] Ladde, G. S., Lakshmikantham, V. and Zhang, B. G. (1987). Oscillation Theory of Differential Equations with Deviating Arguments (Marcel Dekker, Inc., New York).

[163] Lakshmikantham, V., Bainov, D. D. and Simeonov, P. S. (1989). Theory of Impulsive Differential Equations, Series in Modern Applied Mathematics, 6, (World Scientific Publishing Co., Inc., Teaneck, NJ).

[164] Lalli, B. S., Yu, Y. H. and Cui, B. T. (1992). Oscillations of certain partial differential equations with deviating arguments, Bull. Austral. Math. Soc. 46, pp. 373-380.

[165] Leighton, W. (1952). On selfadjoint differential equations of second order, J. London Math. Soc. 27, pp. 37-47.

[166] Levine, H. A. and Payne, L. E. (1976). On the nonexistence of entire solutions to nonlinear second order elliptic equations, SIAM J. Math. Anal. 7, pp. $337-343$.

[167] Li, W. N. (2000). Oscillation properties for systems of hyperbolic differential equations of neutral type, J. Math. Anal. Appl. 248, pp. 369-384.

[168] Li, W. N. (2003). Forced oscillation properties for certain systems of partial functional differential equations, Appl. Math. Comput. 143, pp. 223-232.

[169] Li, W. N. (2005). On the forced oscillation of solutions for systems of impulsive parabolic differential equations with several delays, J. Comput. Appl. Math. 181, pp. 46-57.

[170] Li, W. N. and Cui, B. T. (1999). Oscillation for systems of parabolic equations of neutral type, Southeast Asian Bull. Math. 23, pp. 447-456.

[171] Li, W. N. and Cui, B. T. (1999). Oscillation of solutions of neutral partial functional differential equations, J. Math. Anal. Appl. 234, pp. 123-146.

[172] Li, W. N., Cui, B. T. and Debnath, L. (2003). Oscillation of systems of certain neutral delay parabolic differential equations, J. Appl. Math. Stochastic Anal. 16, pp. 81-94.

[173] Li, W. N. and Debnath, L. (2003). Oscillation of higher-order neutral partial functional differential equations, Appl. Math. Lett. 16, pp. 525-530.

[174] Li, W. N., Han, M. and Meng, F. W. (2004). $H$-oscillation of solutions of certain vector hyperbolic differential equations with deviating arguments, Appl. Math. Comput. 158, pp. 637-653.

[175] Li, W. N., Han, M. and Meng, F. W. (2005). Necessary and sufficient conditions for oscillation of impulsive parabolic differential equations with 
delays, Appl. Math. Lett. 18, pp. 1149-1155.

[176] Li, W. N. and Meng, F. W. (2001). Oscillation for systems of neutral partial differential equations with continuous distributed deviating arguments, Demonstratio Math. 34, pp. 619-633.

[177] Li, W. N. and Meng, F. W. (2003). On the forced oscillation of systems of neutral parabolic differential equations with deviating arguments, J. Math. Anal. Appl. 288, pp. 20-27.

[178] Li, Y. K. (1997). Oscillation of systems of hyperbolic differential equations with deviating arguments, Acta Math. Sinica 40, pp. 100-105.

[179] Ličko, I. and Švec, M. (1963). Le caractère oscillatoire des solutions de l'équation $y^{(n)}+f(x) y^{\alpha}=0, n>1$, Czechoslovak Math. J. 13, pp. 481491.

[180] Liu, A. P., Xiao, L. and Liu, T. (2004). Oscillation of nonlinear impulsive hyperbolic equations with several delays, Electron. J. Differential Equations 2004, No. 24, pp. 1-6.

[181] Liu, B. (1994). Oscillatory properties of systems of nonlinear delay parabolic differential equations, Ann. Differential Equations 10, pp. 290298.

[182] Liu, X. and Fu, X. (1996). Oscillation criteria for nonlinear inhomogeneous hyperbolic equations with distributed deviating arguments, J. Appl. Math. Stochastic Anal. 9, pp. 21-31.

[183] Liu, X. and Fu, X. (1998). Oscillation criteria for high order delay partial differential equations, J. Appl. Math. Stochastic Anal. 11, pp. 193-208.

[184] Luo, J. W. (2002). Oscillation of hyperbolic partial differential equations with impulses, Appl. Math. Comput. 133, pp. 309-318.

[185] Mangeron, D. (1968). Problèmes à la frontière concernant les équations polyvibrantes, C. R. Acad. Sci. Paris Sér. A-B 266, pp. 870-873; pp. 976979; pp. 1050-1052; pp. 1103-1106; pp. 1121-1124.

[186] Mař́k, R. (2000). Oscillation criteria for the Schrödinger PDE, Adv. Math. Sci. Appl. 10, pp. 495-511.

[187] Mař́k, R. (2000). Hartman-Wintner type theorem for PDE with $p$ Laplacian, Electron. J. Qual. Theory Differ. Equ. No. 18, pp. 1-7.

[188] Mař́k, R. (2000). Oscillation criteria for PDE with $p$-Laplacian via the Riccati technique, J. Math. Anal. Appl. 248, pp. 290-308.

[189] Mař́k, R. (2002). Positive solutions of inequality with $p$-Laplacian in exterior domains, Math. Bohem. 127, pp. 597-604.

[190] Mař́k, R. (2002). Oscillation criteria for a class of nonlinear partial differential equations, Electron. J. Differential Equations 2002, No. 28, pp. $1-10$.

[191] Mařík, R. (2004). Integral averages and oscillation criteria for half-linear partial differential equation, Appl. Math. Comput. 150, pp. 69-87.

[192] Mař́k, R. (2004). Riccati-type inequality and oscillation criteria for a halflinear PDE with damping, Electron. J. Differential Equations 2004, No. 11, pp. $1-17$.

[193] Mař́k, R. (2005). Asymptotic estimates for PDE with $p$-Laplacian and damping, Electron. J. Qual. Theory Differ. Equ. No. 5, pp. 1-6. 
[194] Mařík, R. (2005). Oscillation of the half-linear PDE in general exterior domains - the variational approach, Nonlinear Anal. 60, pp. 485-489.

[195] Mař́k , R. (2006). Interval-type oscillation criteria for half-linear PDE with damping, Appl. Appl. Math. 1, pp. 1-10.

[196] McNabb, A. (1962). A note on the boundedness of solutions of linear parabolic equations, Proc. Amer. Math. Soc. 13, pp. 262-265.

[197] Medeiros, L. A. (1979). On a new class of nonlinear wave equations, $J$. Math. Anal. Appl. 69, pp. 252-262.

[198] Mikusiński, J. (1951). On Fite's oscillation theorems, Colloq. Math. 2, pp. 34-39.

[199] Minchev, E. and Yoshida, N. (2003). Oscillations of solutions of vector differential equations of parabolic type with functional arguments, J. Comput. Appl. Math. 151, pp. 107-117.

[200] Minchev, E. and Yoshida, N. (2003). Oscillations of vector differential equations of hyperbolic type with functional arguments, Math. J. Toyama Univ. 26, pp. 75-84.

[201] Mishev, D. P. (1986). Oscillatory properties of the solutions of hyperbolic differential equations with "maximum", Hiroshima Math. J. 16, pp. 77-83.

[202] Mishev, D. P. (1989). Oscillation of the solutions of hyperbolic differential equations of neutral type with "maxima", Godishnik Vissh. Uchebn. Zaved. Prilozhna Mat. 25, pp. 9-18.

[203] Mishev, D. P. (1989). Oscillation of the solutions of parabolic differential equations of neutral type with "maxima", Godishnik Vissh. Uchebn. Zaved. Prilozhna Mat. 25, pp. 19-28.

[204] Mishev, D. P. (1991). Necessary and sufficient conditions for oscillation of neutral type of parabolic differential equations, C. R. Acad. Bulgare Sci. 44, pp. 11-14.

[205] Mishev, D. P. (1991). Oscillation of the solutions of neutral type hyperbolic differential equations, Math. Balkanica 5, pp. 121-128.

[206] Mishev, D. P. (1992). Oscillation of the solutions of non-linear parabolic equations of neutral type, Houston J. Math. 18, pp. 259-269.

[207] Mishev, D. P. and Bainov, D. D. (1984). Oscillation properties of the solutions of hyperbolic equations of neutral type, Proceedings of the Colloquium on Qualitative Theory of Differential Equations, Szeged, pp.771-780.

[208] Mishev, D. P. and Bainov, D. D. (1986). Oscillation properties of the solutions of a class of hyperbolic equations of neutral type, Funkcial. Ekvac. 29, pp. 213-218.

[209] Mishev, D. P. and Bainov, D. D. (1988). Oscillation of the solutions of parabolic differential equations of neutral type, Appl. Math. Comput. 28, pp. $97-111$.

[210] Mishev, D. P. and Bainov, D. D. (1992). A necessary and sufficient condition for oscillation of neutral type hyperbolic equations, Rend. Mat. 12, pp. $545-553$.

[211] Naito, M., Naito, Y. and Usami, H. (1997). Oscillation theory for semilinear elliptic equations with arbitrary nonlinearities, Funkcial. Ekvac. 40, pp. 41-55. 
[212] Naito, M. and Yoshida, N. (1978). Oscillation theorems for semilinear elliptic differential operators, Proc. Roy. Soc. Edinburgh Sect. A 82, pp. 135-151.

[213] Naito, M. and Yoshida, N. (1989). Oscillation criteria for a class of higher order elliptic equations, Math. Rep. Toyama Univ. 12, pp. 29-40.

[214] Naito, Y. and Usami, H. (2001). Oscillation criteria for quasilinear elliptic equations, Nonlinear Anal. 46, pp. 629-652.

[215] Narazaki, T. (1981). On the time global solutions of perturbed beam equations, Proc. Fac. Sci. Tokai Univ. 16, pp. 51-71.

[216] Narita, M. (1978). Oscillation theorems for semilinear hyperbolic and ultrahyperbolic operators, Bull. Austral. Math. Soc. 18, pp. 55-64.

[217] Narita, M. and Yoshida, N. (1979). Oscillation theorems for linear ultrahyperbolic operators, Utilitas Math. 15, pp. 143-159.

[218] Narita, M. and Yoshida, N. (1979). Oscillation of semilinear ultrahyperbolic differential operators, Ann. Mat. Pura Appl. 122, pp. 289-300.

[219] Nasr, A. H. (1998). Sufficient conditions for the oscillation of forced superlinear second order differential equations with oscillatory potential, Proc. Amer. Math. Soc. 126, pp. 123-125.

[220] Noussair, E. S. (1971). Oscillation theory of elliptic equations of order $2 m$, J. Differential Equations 10, pp. 100-111.

[221] Noussair, E. S. (1975). Oscillation of elliptic equations in general domains, Canad. J. Math. 27, pp. 1239-1245.

[222] Noussair, E. S. and Swanson, C. A. (1972). Oscillation theorems for vector differential equations, Utilitas Math. 1, pp. 97-109.

[223] Noussair, E. S. and Swanson, C. A. (1976). Oscillation theory for semilinear Schrödinger equations and inequalities, Proc. Roy. Soc. Edinburgh Sect. A 75, pp. 67-81.

[224] Noussair, E. S. and Swanson, C. A. (1976). Oscillation of nonlinear vector differential equations, Ann. Mat. Pura Appl. 109, pp. 305-315.

[225] Noussair, E. S. and Swanson, C. A. (1980). Oscillation of semilinear elliptic inequalities by Riccati transformations, Canad. J. Math. 32, pp. 908-923.

[226] Noussair, E. S. and Yoshida, N. (1975). Nonoscillation criteria for elliptic equations of order 2m, Atti Accad. Naz. Lincei Rend. Cl. Sci. Fis. Mat. Natur. 59, pp. 57-64.

[227] Oğuztöreli, M. N. and Easwaran, S. (1971). A Goursat problem for a high order Mangeron equation, Atti Accad. Naz. Lincei Rend. Cl. Sci. Fis. Mat. Natur. 50, pp. 650-653.

[228] Okikiolu, G. O. (1971). Aspects of the Theory of Bounded Integral Operators in $L^{p}$-spaces (Academic Press, New York).

[229] Onose, H. (1975). A comparison theorem and the forced oscillation, Bull. Austral. Math. Soc. 13, pp. 13-19.

[230] Onose, H. (1982). Oscillation criteria for the sublinear Schrödinger equation, Proc. Amer. Math. Soc. 85, pp. 69-72.

[231] H. Onose, (1993). Oscillation of nonlinear functional differential equations, GAKUTO Internat. Ser. Math. Sci. Appl. 2, pp. 637-642.

[232] Onose, H. and Yokoyama, E. (1976). Oscillation of partial differential in- 
equalities, Tamkang J. Math. 7, pp. 67-70.

[233] Pagan, G. (1973). Oscillation theorems for characteristic initial value problems for linear hyperbolic equations, Atti Accad. Naz. Lincei Rend. Cl. Sci. Fis. Mat. Natur. 55, pp. 301-313.

[234] Pagan, G. (1976). Existence of nodal lines for solutions of hyperbolic equations, Amer. Math. Monthly 83, pp. 358-359.

[235] Pagan, G. (1977). An oscillation theorem for characteristic initial value problems in linear hyperbolic equations, Proc. Roy. Soc. Edinburgh Sect. A 77, pp. 265-271.

[236] Pagan, G. and Stocks, D. (1979). Oscillation criteria for second order hyperbolic initial value problems, Proc. Roy. Soc. Edinburgh Sect. A 83, pp. 239-244.

[237] Parhi, N. and Kirane, M. (1994). Oscillatory behaviour of solutions of coupled hyperbolic differential equations, Analysis 14, pp. 43-56.

[238] Petrova, Z. A. (2005). Oscillations of a class of sublinear and superlinear hyperbolic equations, C. R. Acad. Bulgare Sci. 58, pp. 251-256.

[239] Philos, Ch. G. (1989). Oscillation theorems for linear differential equations of second order, Arch. Math. (Basel) 53, pp. 482-492.

[240] Picone, M. (1909). Sui valori eccezionali di un parametro da cui dipende un'equazione differenziale lineare ordinaria del second'ordine, Ann. Scuola Norm. Sup. Pisa 11, pp. 1-141.

[241] Picone, M. (1911). Un teorema sulle soluzioni delle equazioni lineari ellittiche autoaggiunte alle derivate parziali del secondo-ordine, Atti Accad. Naz. Lincei Rend. Cl. Sci. Fis. Mat. Natur. 20, pp. 213-219.

[242] Protter, M. H. and Weinberger, H. F. (1984). Maximum Principles in Differential Equations (Springer-Verlag, New York).

[243] Shoukaku, Y. (2003). On the oscillatory properties of parabolic equations with continuous distributed arguments, Math. J. Toyama Univ. 26, pp. 93-107.

[244] Shoukaku, Y. and Yoshida, N. (2003). Oscillatory properties of solutions of nonlinear parabolic equations with functional arguments, Indian J. Pure Appl. Math. 34, pp. 1469-1478.

[245] Shoukaku, Y. and Yoshida, N. (2005). Oscillations of parabolic systems with functional arguments, Toyama Math. J. 28, pp. 105-131.

[246] Shoukaku, Y. and Yoshida, N. (2006). Oscillations of hyperbolic systems with functional arguments, Appl. Appl. Math. 1, pp. 83-95.

[247] Śliwiński, E. (1964). On some oscillation problems for the equation $\Delta^{(n)} u-$ $f(r) u=0$ in a three-dimensional space, Prace Mat. 8, pp. 119-120.

[248] Suleumanov, N. M. (1979). On the behavior of solutions of second order nonlinear elliptic equations with linear principal part, Soviet Math. Dokl. 20, pp. $815-819$.

[249] Sturm, C. (1836). Sur les équations différentielles linéaires du second ordre, J. Math. Pures Appl. 1, pp. 106-186.

[250] Švaňa, P. (1988). Oscillation criteria for forced nonlinear elliptic equations of arbitrary order, Časopis Pěst. Mat. 113, pp. 169-178.

[251] Swanson, C. A. (1968). Comparison and Oscillation Theory of Linear Dif- 
ferential Equations (Academic Press, New York).

[252] Swanson, C. A. (1973). Strong oscillation of elliptic equations in general domains, Canad. Math. Bull. 16, pp. 105-110.

[253] Swanson, C. A. (1975). Picone's identity, Rend. Mat. 8, pp. 373-397.

[254] Swanson, C. A. (1979). Semilinear second order elliptic oscillation, Canad. Math. Bull. 22, pp. 139-157.

[255] Swanson, C. A. (1983). Criteria for oscillatory sublinear Schrödinger equations, Pacific J. Math. 104, pp. 483-493.

[256] Tanaka, S. (1997). Oscillation properties of solutions of second order neutral differential equations with deviating arguments, Analysis 17, pp. 99-111.

[257] Tanaka, S. (1997). Forced oscillations of first order nonlinear neutral differential equations, J. Appl. Anal. 3, pp. 23-41.

[258] Tanaka, S. and Yoshida, N. (1997). Oscillations of solutions to parabolic equations with deviating arguments, Tamkang J. Math. 28, pp. 169-181.

[259] Tao, Y. and Yoshida, N. (2005). Oscillation of nonlinear hyperbolic equations, Toyama Math. J. 28, pp. 27-40.

[260] Tao, Y. and Yoshida, N. (2006). Oscillation criteria for hyperbolic equations with distributed deviating arguments, Indian J. Pure Appl. Math. 37, pp. 291-305.

[261] Timoshenko, S., Young, D. H. and Weaver, Jr., W. (1974). Vibration Problems in Engineering, Fourth Edition (Wiley, New York).

[262] Toraev, A. (1981). On the oscillation of solutions of higher order equations of elliptic type, Soviet Math. Dokl. 24, pp. 195-198.

[263] Tramov, M. I. (1984). Oscillation of solutions of partial differential equations with deviating argument, Differ. Uravn. 20, pp. 721-723.

[264] Travis, C. C. (1974). Comparison and oscillation theorems for hyperbolic equations, Utilitas Math. 6, pp. 139-151.

[265] Travis, C. C. and Yoshida, N. (1981). Oscillation criteria for third order hyperbolic characteristic initial value problems, Proc. Roy. Soc. Edinburgh Sect. A 88, pp. 135-140.

[266] Travis, C. C. and Yoshida, N. (1982). Oscillation criteria for nonlinear Bianchi equations, Nonlinear Anal. 6, pp. 625-636.

[267] Travis, C. C. and Young, E. C. (1978). Comparison theorems for ultrahyperbolic equations, Internat. J. Math. Math. Sci. 1, pp. 31-40.

[268] Trench, W. F. (1974). Canonical forms and principal systems for general disconjugate equations, Trans. Amer. Math. Soc. 189, pp. 319-327.

[269] Uesaka, H. (1996). Oscillation of solutions of nonlinear wave equations, Proc. Japan Acad. Ser. A 72, pp. 148-151.

[270] Uesaka, H. (1997). Oscillatory behavior of solutions of nonlinear wave equations, Nonlinear Anal. 30, pp. 4655-4661.

[271] Uesaka, H. (2001). A pointwise oscillation property of semilinear wave equations with time-dependent coefficients II, Nonlinear Anal. 47, pp. 25632571.

[272] Uesaka, H. (2003). A pointwise oscillation property of semilinear wave equations with time-dependent coefficients, Nonlinear Anal. 54, pp. 1271-1283.

[273] Uesaka, H. (2004). Oscillation or nonoscillation property for semilinear 
wave equations, J. Comput. Appl. Math. 164-165, pp. 723-730.

[274] Usami, H. (1995). Nonexistence properties of positive solutions and oscillation criteria for second order semilinear elliptic inequalities, Arch. Rational Mech. Anal. 130, pp. 277-302.

[275] Usami, H. (1998). Some oscillation theorems for a class of quasilinear elliptic equations, Ann. Mat. Pura Appl. 175, pp. 277-283.

[276] van der Waerden, B. L. (1960). Algebra I (Springer-Verlag, Berlin).

[277] Wachnicki, E. (1976). On the oscillatory properties of solutions of certain elliptic equations, Comment. Math. Prace Mat. 9, pp. 165-169.

[278] Wang, P. G. (1999). Forced oscillation of a class of delay hyperbolic equation boundary value problem, Appl. Math. Comput. 103, pp. 15-25.

[279] Wang, P. G. (2000). Oscillation of certain neutral hyperbolic equations, Indian J. Pure Appl. Math. 31, pp. 949-956.

[280] Wang, P. G. and Feng, C. H. (2000). Oscillation of parabolic equations of neutral type, J. Comput. Appl. Math. 126, pp. 111-120.

[281] Wang, P. G. and Yu, Y. H. (1999). Oscillation criteria for a nonlinear hyperbolic equation boundary value problem, Appl. Math. Lett. 12, pp. 91-98.

[282] Wang, T. M. and Gagnon, L. W. (1978). Vibrations of continuous Timoshenko beams on Winkler-Pasternak foundations, J. Sound Vibration 59, pp. $211-220$.

[283] Wintner, A. (1949). A criterion of oscillatory stability, Quart. J. Appl. Math. 7, pp. 115-117.

[284] Wong, J. S. W. (2001). On Kamenev-type oscillation theorems for secondorder differential equations with damping, J. Math. Anal. Appl. 258, pp. 244-257.

[285] Wu, J. (1996). Theory and Applications of Partial Functional Differential Equations (Springer-Verlag, New York).

[286] Xie, S. L. and Cheng, S. S. (1995). Oscillation of a logistic equation with delay and diffusion, Ann. Polon. Math. 62, pp. 219-230.

[287] Xu, Z. T. (2005). The oscillatory behavior of second order nonlinear elliptic equations, Electron. J. Qual. Theory Differ. Equ. No. 8, pp. 1-11.

[288] Xu, Z. T. (2006). Oscillation of second-order elliptic equations with damping terms, J. Math. Anal. Appl. 317, pp. 349-363.

[289] Xu, Z. T. (2006). Riccati inequality and oscillation criteria for PDE with p-Laplacian, J. Inequal. Appl. 2006, pp. 1-10.

[290] Xu, Z. T. (2006). On the oscillation of second order quasilinear elliptic equations, Math. Comput. Modelling 43, pp. 30-41.

[291] Xu, Z. T. and Xing, H. Y. (2003). Oscillation criteria of Kamenev-type for PDE with p-Laplacian, Appl. Math. Comput. 145, pp. 735-745.

[292] Yan, L. and Yoshida, N. (2006). Oscillations of characteristic initial value problems for hyperbolic equations with delays, Indian J. Pure Appl. Math. 37, pp. 357-367.

[293] Ye, Q. X. and Li, Z. Y. (1990). Introduction to Reaction-Diffusion Equations (Beijing Science Press, Beijing).

[294] Yoshida, N. (1976). Nonoscillation and comparison theorems for a class of 
higher order elliptic systems, Japan. J. Math. (N.S.) 2, pp. 419-434.

[295] Yoshida, N. (1979). An oscillation theorem for characteristic initial value problems for nonlinear hyperbolic equations, Proc. Amer. Math. Soc. 76, pp. 95-100.

[296] Yoshida, N. (1983). Oscillation properties of solutions of second order elliptic equations, SIAM J. Math. Anal. 14, pp. 709-718.

[297] Yoshida, N. (1984). An oscillation theorem for sublinear elliptic differential inequalities, Bull. Austral. Math. Soc. 30, pp. 387-394.

[298] Yoshida, N. (1985). Forced oscillations of extensible beams, SIAM J. Math. Anal. 16, pp. 211-220.

[299] Yoshida, N. (1985). Forced oscillations of nonlinear extensible beams, Proceedings of the Tenth International Conference on Nonlinear Oscillations (Varna, 1984), Sofia, pp. 814-817.

[300] Yoshida, N. (1986). Oscillation of nonlinear parabolic equations with functional arguments, Hiroshima Math. J. 16, pp. 305-314.

[301] Yoshida, N. (1987). On the zeros of solutions to nonlinear hyperbolic equations, Proc. Roy. Soc. Edinburgh Sect. A 106, pp. 121-129.

[302] Yoshida, N. (1987). Forced oscillations of solutions of parabolic equations, Bull. Austral. Math. Soc. 36, pp. 289-294.

[303] Yoshida, N. (1987). Oscillation properties of solutions of characteristic initial value problems, Proceedings of the Eleventh International Conference on Nonlinear Oscillations (Budapest, 1987), Budapest, pp. 527-530.

[304] Yoshida, N. (1987). Forced oscillations of solutions of second order elliptic equations, Appl. Anal. 25, pp. 149-155.

[305] Yoshida, N. (1988). On the zeros of solutions of beam equations, Ann. Mat. Pura Appl. 151, pp. 389-398.

[306] Yoshida, N. (1990). On the zeros of solutions of hyperbolic equations of neutral type, Differential Integral Equations 3, pp. 155-160.

[307] Yoshida, N. (1992). Oscillatory properties of solutions of certain elliptic equations, Bull. Austral. Math. Soc. 45, pp. 297-303.

[308] Yoshida, N. (1992). Forced oscillations of parabolic equations with deviating arguments, Math. J. Toyama Univ. 15, pp. 131-142.

[309] Yoshida, N. (1993). On the zeros of solutions of hyperbolic equations with deviating arguments, Math. J. Toyama Univ. 16, pp. 125-133.

[310] Yoshida, N. (1994). On the zeros of solutions of elliptic equations with deviating arguments, J. Math. Anal. Appl. 185, pp. 570-578.

[311] Yoshida, N. (1995). Forced oscillations of nonlinear parabolic equations with functional arguments, Analysis 15, pp. 71-84.

[312] Yoshida, N. (1995). On the oscillation of solutions to parabolic equations with functional arguments, Math. J. Toyama Univ. 18, pp. 65-78.

[313] Yoshida, N. (1995). Oscillation of partial functional-differential equations with deviating arguments, Tamkang J. Math. 26, pp. 131-139.

[314] Yoshida, N. (1996). Nonlinear oscillation of first order delay differential equations, Rocky Mountain J. Math. 26, pp. 361-373.

[315] Yoshida, N. (1996). On the zeros of solutions of initial value problems for hyperbolic equations in one-dimensional space, Math. J. Toyama Univ. 19, 
pp. $179-189$.

[316] Yoshida, N. (1997). Zeros of solutions of hyperbolic equations with functional arguments, AMS/IP Stud. Adv. Math. 3, pp. 613-617.

[317] Yoshida, N. (1997). Oscillation of partial functional differential equations, Math. J. Toyama Univ. 20, pp. 107-139.

[318] Yoshida, N. (1999). Forced oscillations of a class of parabolic equations with functional arguments, Math. J. Toyama Univ. 22, pp. 187-204.

[319] Yoshida, N. (2001). Oscillation criteria for a class of hyperbolic equations with functional arguments, Kyungpook Math. J. 41, pp. 75-85.

[320] Yoshida, N. (2003). Oscillation of half-linear partial differential equations with first order terms, Stud. Univ. Žilina 17, pp. 177-184.

[321] Yoshida, N. (2006). Picone-type inequalities for a class of quasilinear elliptic equations and their applications, Proceedings of the Conference on Differential \& Difference Equations and Applications (Florida, 2005), New York, pp. 1177-1185.

[322] Yoshida, N. (2007). Oscillation criteria for half-linear partial differential equations via Picone's identity, Proceedings of Equadiff 11 (Bratislava, 2005), Bratislava, pp. 589-598.

[323] Yoshida, N. (2007). Picone-type inequality and oscillation theorems for a class of quasilinear elliptic equations, Proceedings of the Colloquium on Differential and Difference Equations (Brno, 2006): Folia Fac. Sci. Natur. Univ. Masaryk. Brun. Math. 16, pp. 193-200.

[324] Yoshida, N. (2007). Oscillations and unboundedness of solutions of superlinear-sublinear parabolic equations via Picone-type inequality, Toyama Math. J. 30, pp. 77-87.

[325] Zhang, B. G. and Zhou, Y. (2007). Qualitative Analysis of Delay Partial Difference Equations (Hindawi Publishing Corporation, New York).

[326] Zhang, L. Q. (2000). Oscillation criteria for hyperbolic partial differential equations with fixed moments of impulse effects, Acta Math. Sinica 43, pp. $17-26$.

[327] Zuazua, E. (1990). Oscillation properties for some damped hyperbolic equations, Houston J. Math. 16, pp. 25-52. 


\section{Index}

advanced part, 113

algebraic equation, 27

annular domain, 3, 4

ball, 101

beam equation, 221

Bessel function, 63, 75

beta function, 270

Bianchi equation, 78

biharmonic operator, 27, 32

boundary condition, 39,51

boundary value problem, 39, 51, 116

characteristic initial value problem, 65,79

characteristic polynomial, 29

clamped end, 95

conormal derivative, 52, 76

constant coefficients, 27

convex function, 6

coupled beam equations, 100

Courant's minimum principle, 2

cylindrical domain, 51, 91

d'Alembert's formula, 65

damped, 257

damping term, 257

delay hyperbolic equations, 179

delays, 179

deviating argument, 101

Dirac function, 20

Dirichlet, 228 divergence, 22

divergence theorem, 5

Duffing's equation, 95, 124

eigenfunction, 40

eigenvalue problem (EVP), 40, 110

Euclidean length, 4

eventually negative, 5,146

eventually positive, 5,146

extensible beam equation, 91

exterior domain, 4, 10

Ferrari's formula, 29

first eigenvalue, 40

forced oscillation, 124, 136

forcing terms, 192

fourth order, 32

free end, 95

functional arguments, 109, 116, 124,

$136,152,161,185,192,221,227$

fundamental solution, 20

gamma function, 5

gradient, 21

Green function, 21, 45

Green's formula, 40

Hölder's inequality, 294

half-linear, 239, 250, 257

heat equation, 45

higher order, 27, 32, 85, 90

higher order equations, 207 
hinged end, 91, 221

$H$-oscillation, 152

$H$-oscillatory, 153, 222

hyperbolic equation, 51, 85, 185, 192

hyperbolic systems, 221, 227

hyperspherical coordinates, 2, 5

impulsive differential inequality, 149, 201

impulsive hyperbolic equation, 198

impulsive parabolic equation, 145

initial value problem, 44, 62

iterated Laplacian, 27, 32

Jensen's inequality, 7, 25, 120

kernel function, 296

Kronecker's delta, 4

Laplacian, 3

linear elliptic equation, 1

metaharmonic operator, 27, 32

nabla, 10

Neumann, 228

neutral type, 130, 187

nodal domain, 1

nodally nonoscillatory, 4

nodally oscillatory, 1

nonlinear hyperbolic equation, 54

nonoscillatory, 20, 39, 147, 199, 276

oscillating coefficients, 109

oscillatory, 4, 39, 44, 66, 76, 79, 110,

$147,199,245,255$

oscillatory at $r=\infty, 3,20$

oscillatory at $t=\infty, 46$

parabolic equation, 39

parabolic systems, 152, 161, 282

periodic, 124

perturbed elliptic equation, 14

Picone identity, 240, 250, 257, 283, 288

Picone-type inequality, 266, 271, 276
p-Laplacian, 239

prepared, 283

$P$-sphere, 21

quasilinear parabolic equation, 275

radially symmetric solution, 245

real part, 284

rectangular domain, 101

retarded part, 118

Riccati method, 291

Riccati-type equation, 291

Riccati-type inequality, 292

Robin, 228

Schwarz's inequality, 154, 261

sgn (signum), 14

sliding end, 95

Sobolev space $W_{0}^{1, \alpha+1}(G), 242,252$

sphere $S_{r}, 3$

spherical mean, 3, 5, 10, 245

Sturmian comparison theorem, 241,

244, 251, 254

sublinear elliptic equation, 9,26

superlinear elliptic equation, 4, 9, 265

superlinear-sublinear, 270, 274

Timoshenko beam equation, 96

trace, 286

ultrahyperbolic equation, 75

unbounded, 193, 286, 289

unboundedness, 282

uniformly elliptic, 20

unit sphere, 3

variable coefficients, 20

vector hyperbolic equation, 221

vector parabolic equation, 152

volume, 42

wave equation, 55

weakly oscillatory, 163, 229

Young's inequality, 261, 297 